\title{
ENGINEERING
}

\section{Role of Extreme Pressure Lubricants in Boundary Lubrication and in Metal Cutting}

ReBinder et al. ${ }^{1}$ have examinod the effects of surfaceactive agents such as mineral oil solutions of oleic acid to alter the creep and fatigue character of motals. Observed. changes are attributed to the adsorption of oleic acid by the metal, thereby hastening the strain-hardening of the metal's surface.

In metal cutting, the roduction of tool forces is attributed by Rebinder et al. ${ }^{2}$ to the intensification of strain-hardening in the cutting zone by these agents, while the contributions made to tool force reductions as a result of the lubricant's action to reduce friction is regarded as unimportant ${ }^{2}$.

Little attention has been paid by these investigators to liquids of other types, containing labilo atoms of sulphur or chlorine, which are commonly regarded as effective metal-cutting fluids and extreme pressure or boundary lubricants. We have examined the effect of such liquids to modify the shear-strength of metals and a clearer picture of the part played by these liquids in boundary lubrication and metal-cutting has emorged from these studies.

The instrument used in these studies is shown schematically in Fig. 1A. A metal specimen $\frac{1}{8}$ in. $\times \frac{3}{8}$ in. $\times 2 \frac{1}{4}$ in. made of steel, aluminium, etc., protrudes approximately 1 in. above the surface of a split block, which clamps it tightly. The specimon yields plastically, as in a hardness test measurement, to form a V-shaped notch when the hardened tool-steel indenter, having $0 \cdot 25$-in. ${ }^{2}$ cross-section, is loaded hydraulically into the centred specimen at $2 \mathrm{in}$./ min, Fig. 1B. The indenter's knife-edge overhangs the front and back of the specimen.

Shear-failure of cold-rolled steel takes place, with the production of a tiny chip (see Fig. 1C) when the applied
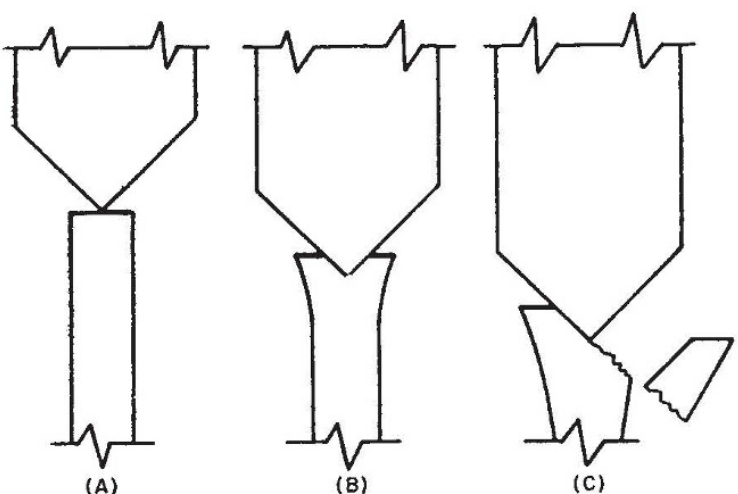
Fig. 1. $A$, Schematic diagram of shear-failure tester; $B$, plastic de-
formation of a specimen under load; $C$, shear-failure resulting from deformation in the presence of carbon tetrachloride

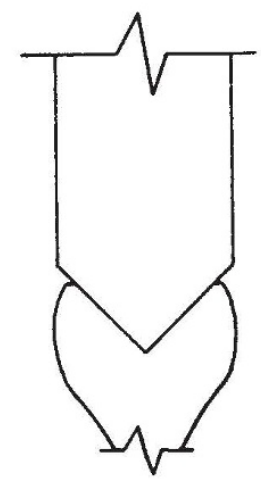

Fig. 2. Deformation in air with no failure of the specimen at $7,000 \mathrm{lb}$. load, which is increased continuously, reaches 4,400 lb. \pm 2 per cent, provided that carbon tetrachloride saturates the specimen-indenter zone. No such shear-failure occurs in air, however, but only further deformation, as shown in Fig. 2, even at loads as high as 7,000 lb., provided that proper attention is paid to the cleanliness of the tool.

It is significant that the deformation of all specimens is the same, whether the deformation is conducted in air or in carbon tetrachloride, for loads up to at least $200 \mathrm{lb}$. short of the carbon tetrachloride shear-failure load. The deformation is judged both in torms of build-up of load compared with tool advance into the specimen, and from microphotographs of etched specimens that have boen deformed.

For this and other reasons it has been concluded that the loading forces required to shear metal which has boen strained is determined largely by the interaction between the environment and metal at points of maximum shearstress. However, the process is not due to an acceleration of strain-hardoning, as proposed by Rebinder, and is not due to the formation of a low shear-strength film along the tool-chip interface, as is commonly accepted in explaining reduced forcos in problems of this nature which deal with boundary lubrication ${ }^{3}$. Rather, the source of activity arises from the generation of products, such as ferric chloride, formed during creation of fresh metal surfaces in the presence of lubricant, which stabilize micro-cracks generated prior to shear-failure in much the way liquid metals function in the embrittlement of aluminium 4 . This leads to shear at reduced stress-levels. The same mechanism applies in the case of surface-active agents.

Extrome pressure lubricants, therefore, because of their low-stress micro-crack stabilization factor, will reduce the friction, wear, and metal transfer of sliding surfaces by promoting the rapid shear-failure of welded asperities, of the type envisaged by Greenwood and Tabor ${ }^{5}$, at reduced stress-levels, before build-up of the junction becomes extensive. Hence, cutting fluids reduce tool forces by promoting the shear-failure of the work-pisce ahead of the tool-tip and the shear-failure of numerous welded asperitios arising during chip-flow over the tool face, all at reduced stress-levels, with the former effoct believed to be the more important.

Sun Oil Co.,

E. M. KOHN

Marcus Hook,

Pennsylvania.

' Likhtman, V. I., Rebinder, P. A., and Karpenko, G. V., Effeet of Surface Active Media on the Deformation of Metals (Chemical Publishing Co., 1960).

${ }^{2}$ Epifanov, G. I., Pleteneva, N. A., and Rebinder, P. A., Mechanisms of Active Agents in the Cutting of Metals (Brutcher Transl. No. 3424). ${ }^{3}$ Bowden, F. P., and Tabor, D., Friction and Lubrication (Methuen, 1956). - Rostoker, W., MeCaughey, J. M., Markus, H., Embrittlement by Liquid Metals (Reinhold, 1960).

${ }^{5}$ Greenwood, J. A., and Tabor, D., Proc. Conf. Lubrication and Wear, Paper 92 (1957).

\section{RADIATION CHEMISTRY}

\section{Dehydropeptide Production in the Radiolysis of Solid Peptides : a Radiolytic Synthesis of Pyrazine Derivatives from Cyclic Dipeptides}

Amona the chemical changes observed on radiolysis of compounds containing the peptide bond are those attributod $^{1-3}$ to the production of unsaturated linkages which may be represented in terms of the tautomeric structuros, $\sim \mathrm{CON}=\mathrm{C}\left(\mathrm{CH}_{2} R\right) \sim \rightleftarrows \sim \mathrm{CONH}-\mathrm{C}(=\mathrm{CH} R) \sim$. Com. pounds containing this type of chemical function have boen designated dehydropeptides; such compounds are stable in water yet are readily hydrolysed to yield ammonia and a carbonyl product on heating in dilute mineral acid, $\sim \mathrm{CON}=\mathrm{C}\left(\mathrm{CH}_{2} R\right) \sim+2 \mathrm{H}_{2} \mathrm{O} \rightarrow \sim \mathrm{COOH}+\mathrm{NH}_{3}+R \mathrm{CH}_{2}$ $\mathrm{CO} \sim$ (ref. 4). The experimental evidence for production of dehydropeptides in tho radiolysis of proteins and simpler peptide systems has recently been reviewed ${ }^{5}$. Identifica- 